\title{
A new approach to understanding teachers' classroom practices
}

Lyla Alsalim

\begin{abstract}
Teaching is generally considered a complex practice that involves the constant and dynamic interaction between the teacher, the students and the subject matter. One of the main goals of most education reform initiatives has been to change teachers' classroom practices. Most recent reform curricula focus on highlighting teacher practices that promote and evoke students' understanding alongside the changes in content (Tirosh \& Graeber, 2003). Changes to a teacher's role that are included in the education reform movement call for more research in order to understand and theorise teachers' classroom practices. In this paper, I will present patterns-of-participation $(\mathrm{PoP})$ as a promising framework that aims to understand the role of the teacher for emerging classroom practices. Instead of relying on a traditional approach to understanding classroom practices by analysing teachers' beliefs, this framework applies a participatory approach to look for patterns in the participation of individual teachers in many social practices at the school and in the classroom. Some of these practices are directly related to the teaching and learning of mathematics while others are not. And some of them relate to communities that are not actually present in the classroom or at the school. PoP views teachers' social interaction in a certain community as a piece which is influenced by other pieces of social interactions. In every interaction, the 'pieces' shape a 'fluctuating pattern' that shows the shifting impact of different, previous practices and the dynamic relations between them (Skott, 2010; 2011; 2013).
\end{abstract}

\section{Introduction}

Teaching is generally considered a complex practice that involves the constant and dynamic interaction between the teacher, the students and the subject matter. One of the main goals of most education reform initiatives has been to change teachers' classroom practices. In the past, educators viewed changing the curriculum as an endeavour to change the content of instruction more than the teacher's classroom practices. However, most recent reform curricula focus on highlighting teacher practices that promote and evoke students' understanding of mathematics alongside the changes in content (Tirosh \& Graeber, 2003). Changes to a teacher's role that are included in the education reform movement call for more research in order to understand and theorise teachers' classroom practices. Skott (2010; 2011; 2013) presents patterns-ofparticipation ( $\mathrm{PoP}$ ) as a promising framework that aims to understand the role of the teacher for emerging classroom practices. Instead of relying on a traditional approach to understanding classroom practices by analysing teachers' knowledge, beliefs, and identity, this framework applies a participatory approach to look for patterns in the participation of individual teachers in many social practices at the school and in the classroom.

In this paper, I will present patterns-of-participation (PoP) as a theoretical framework and outline its potential for explaining and understanding mathematics 
teachers' classroom practices. I will also explain its usefulness and limitations as a framework to understand the role of the teacher for emerging classroom practices.

\section{Patterns-of-participation: Moving away from a belief-practice approach}

Skott $(2010 ; 2011 ; 2013)$ introduced PoP as a promising framework for providing coherent and dynamic theoretical understandings of mathematics teacher practices. Skott's main motivation in developing this framework was to overcome the conceptual and methodological problems of belief research (Skott, 2009; 2010).

Over the last 25 years, there has been a significant amount of research on teachers' beliefs (Skott, 2010). Scholars focusing on belief research assume that teachers' beliefs are a major determinant for teachers' practices in the classroom. As a result, researchers in this area argue that influencing teachers' beliefs could play a crucial role in changing teachers' classroom practices (Lerman, 2002; Wilson \& Cooney, 2002). Skott (2009; 2013) indicates that this research approach was, and continues to be, strongly built on the assumption that teachers' beliefs are a major barrier to educational change, and that research about teachers' beliefs has the potential to find solutions to "the problems of implementation of the new and more process-oriented approach to mathematics instruction" (2009, p. 28).

However, belief research has many unresolved issues and many conceptual and methodological challenges (Skott, 2010; 2011; 2013; Skott et al., 2011). One of the primary challenges researchers encounter when studying beliefs is the diverse meanings of the term (Pajares, 1992; McLeod \& McLeod, 2002). Pajares (1992) argues that to define beliefs is not clear cut and is dependent on the definer. He believes that users of the word belief will often use attitudes, judgements, opinions and perceptions, among others, synonymously. Moreover, Skott (2013) states "belief research is notorious for its conceptual and methodological problems. Beliefs are generally characterised as relatively stable, value-laden, mental constructs, which carry a subjective truth value" (p.548).

Liljedahl, Oesterle and Bernèche (2012) shed light on the contradictions in research regarding the stability of belief. "Authors had no difficulty allowing the ideas that beliefs are stable and beliefs can (and do) change, to coexist within their work, whether these constructs were stated explicitly or existed implicitly within the empirical evidence of their research" (p. 113). Also, in their analysis of literature on research about beliefs, Liljedahl, Oesterle \& Bernèche (2012) indicate that beliefs are continually changing and researchers could not find evidence that indicates the stability of the beliefs systems (Liljedahl, Oesterle \& Bernèche, 2009). As a result, beliefs cannot be clearly defined and no single correct clarification could be found in research about its nature (Pajares, 1992; McLeod \& McLeod, 2002).

Another major challenge when studying beliefs is the difficulty in distinguishing them from knowledge. Thompson (1992) argues that distinguishing beliefs and knowledge is very complex but that the distinction is important for researchers to address since teachers may consider their beliefs to be knowledge. 
Some researchers have questioned the methodologies used for belief attribution. Those researchers imply that researchers and teachers may have different perceptions and understandings of the concept of belief (Speer, 2005). This methodological problem is due to the inherent difficulty of describing teachers' beliefs which leads to the need to employ multiple sources and use a mix of methodologies. Lester (2002) also emphasizes the methodological challenge of studying teachers' beliefs. He indicates that researchers may become entangled in a circular argument of inferring beliefs from the nature of mathematical activity while trying to explain the same activity with regard to a principal construct of beliefs.

With more than two decades of belief research, the field has not yet reached the expectations of researchers (Skott, 2009; 2013). Despite the rich research on belief, we have not yet found answers to some basic questions (Gates, 2006). Although some researchers, such as McLeod \& McLeod (2002), note that there has been significant advancement in the study of beliefs and affect in mathematics learning, the progress can be more noticed in relation to theoretical aspects. Researchers still call for more extensive studies to assure that progress exists in the quality of instruction. However, Skott $(2009 ; 2013)$ views the call for more study after what has already been done in the field of belief research as a negative sign. "To a large extent, then, belief research is still conceived of as a promising field of study. Phrased negatively, however, its stillpromising character suggests that after 20 years of persistent effort, the field has still not lived up to the expectations of its founders" (Skott, 2009, p. 28). In spite of all the efforts made, the belief research approach has not fulfilled its promises.

The challenges and complexity associated with belief research has led some researchers such as Skott $(2009,2010,2011$, and 2013) to call for more social approaches to belief research. Skott (2010) indicates that taking a context-practice approach by adopting the patterns-of-participation framework provides more coherent and dynamic understandings of teaching practices. Furthermore, it will help in resolving some of the conceptual and methodological problems of a belief-practice approach while maintaining an interest in the meta-issues that constitute the field of beliefs. The PoP framework challenges dominant traditional belief research by questioning the very notion of beliefs and its acquisitionist theoretical foundation (Skott, 2010).

\section{Patterns-of-participation: Toward a more social approach for understanding teachers' practices}

Traditionally, the disciplines of psychology and mathematics have dominated research on mathematics education (Kilpatrick, 1992). Toward the end of the 1980s, theoretical frameworks in mathematics education research started to take a more social approach to interpret mathematics teaching and learning (Lerman, 2000). This shift focuses on studying how the social and cultural practices of education shape individual learners, and conversely, how learners impact the shaping of these social and cultural practices.

The rising influence of Vygotsky's work has attracted attention to the social context of learning. It has introduced the field of mathematics education to the importance of anthropology, sociology and cultural psychology (Lerman, 2000). The 
turn towards social aspects in research acknowledges that meaning, thinking, and reasoning are products of social activity and that mathematics teaching and learning is best understood in relation to sociocultural contexts in which it is learned. However, this additional extension of mathematics education research from its foundation of mathematics and cognitive psychology created new challenges for researchers as they try to understand individual activity and trajectories and the historical sociocultural roots of the ways humans think, act, and recognize the world (Lerman, 2000). Lerman stresses that, in general, recent research does not discard psychological theories when studying mathematics learning; to a certain extent, it calls for a sociocultural, discursive psychology in order to allow for the connection between the actions of individuals and groups in the classroom with history and culture. By acknowledging this connection, researchers can understand mathematics teaching and learning as a particular moment in the zoom of a lens (Lerman, 2001).

The social approach of research in mathematics education has progressively promoted the notion that practice is not only a personal individual matter; it is in fact situated in the sociocultural context. Researchers must interpret practice relatively, between individuals and social settings. Although the relationships between individual and social factors of human functioning have generated much debate in mathematics education, it is mainly in relation to student learning (Skott, 2013). Therefore, PoP is a theoretical framework which aims to understand the relationships between teachers' practice and social factors. The PoP framework elaborates on the view that teachers' practices in classrooms are not simple expressions of their desire and personal resources; it also views their practices as adaptations to social conditions in which they work. As noted by Skott (2013), the "teacher contributes to classroom interaction by reengaging in other past and present practices, possibly reinterpreting and transforming them in the process" (p. 548). The framework presents a useful tool to understand the teachers' position for emerging classroom practices that takes into account the multiple perspectives of student learning in educational research.

\section{Patterns-of-participation: Adopting participationism as a metaphor for human functioning}

PoP is a theoretical framework developed in line with several other social approaches to research in mathematics education. It aims to develop a more coherent understanding of the teacher's role for learning and life in mathematics classrooms. This alternative framework emphasizes the emergent nature of classroom practices. To a considerable degree, PoP adopts participationism as a metaphor for human functioning more than mainstream belief research.

The participationist approach of learning has grown from the sociocultural tradition which is mainly based on Vygotsky's theory of human learning (Sfard, 2001, 2008). According to Sfard (1998), “' 'participation' is almost synonymous with 'taking part' and 'being a part,"” and it views learning as a process of becoming a part of a greater whole, part of a certain community" (Sfard, 1998, p.6). This theory rejects the acquisitionists' view of individuals acquiring knowledge. Rather, participationist researchers view the learner as an emerging practitioner trying to get access to "a well- 
defined, historically established form of human doing" (Sfard, 2008, p.78 ). In other words, learning is a gradual transformation of the individual from participation in a collectively applied activity to a similar form of doing, but in which s/he is able to perform on ones' own accord (Sfard, 1998).

Wenger's (1998) view of the notion practice and participation has influenced Skott's ideas of PoP. Wenger perceives practice as embedded in a community, which is further recognized by a shared goal, common engagement, and a united repertoire. Practice "is a set of frameworks, ideas, tools, information, styles, language, stories, and documents that community members share" (Wenger et al., 2002, p.29). Practice is a way of talking about mutual, historical and social resources, frameworks and views that can maintain mutual engagement in action. Learners in a particular community share a basic body of knowledge that generates a shared foundation which allows members to work together productively (Wenger 1998).

The notions of practice and participation are basic constructs in the origins of PoP. The term practice in PoP holds the same meaning as when researchers use it in social practice theory, as a social phenomenon. Skott et al. (2011) consider practice as an outcome of individual and communal meaning-making and agency that emerges in the local social environment. Skott's understanding of the concept of practice leads to the conclusion that teachers' practice is not directly linked to any individual in the school or classroom community. Teachers' practice in classrooms is a result of their classroom interaction by re-engaging other past and present experiences and reinterpreting and transforming these experiences in the process. A teacher's practice is impacted by and bound together by their re-engagement in other essential discourses and practices through the meaning they place on the social interaction itself.

PoP also gets inspiration from Blumer's (1969) theory symbolic interactionism in order to understand how a teacher's immediate social interaction connects to his/her engagement in past and present practices (Skott, 2013). Mead and Blumer (1969) presented the symbolic interactionism theory as an alternative to the uncritical behaviourism approach which was common in sociology during that era. Blumer (1969) highlighted the interpretive process in the construction of meaning of the depth and diversity of social experience as it was lived. The basic philosophy of symbolic interactionism is that humans should be regarded in the context of their environment and that individuals and the context in which they exist in are inseparable (Blumer, 1969).

From this perspective, PoP takes into account that a "teacher negotiates classroom practices by interpreting the students' and her own possible contributions to the interactions symbolically" (Skott, 2013). PoP analyzes teachers' specific practices in relation to other classroom practices that teachers engage in simultaneously. The teacher also takes the attitude of individual and generalised others and relates it to practices generated from other social interactions such as interactions with other teachers, and from meetings with the parents or the school management. 


\section{The extended PoP framework: including knowledge and identity}

Skott initially developed the patterns-of-participation framework in relation to teachers' beliefs. However, in order to develop a more coherent approach to understand teachers' practices, Skott (2013) extended the framework to include knowledge and identity. Skott (2013) notes that research on teachers has mainly focused on studying three relatively distinct domains: teachers' knowledge, beliefs, and identity. This leads to some incoherence that negatively influences the understanding of the teachers' role in classrooms. Skott presents PoP as a coherent, participatory framework that is capable of dealing with matters usually faced in the distinct fields of teachers' knowledge, beliefs, and identity.

While research on teachers' mathematical knowledge is mainly concerned with the specifics of teachers' content preparation, since the 1980s, it has also investigated some meta-issues such as teachers' conceptions of mathematics and its teaching and learning in the classroom. The teacher-knowledge perspective has become one of the main approaches to thinking about teachers and their practice (Ball et al., 2008).

Skott (2013) notes that focusing solely on constructs of different types of knowledge when examining teachers' knowledge for teaching mathematics provides a limited view of what really happens in mathematics classrooms. Therefore, the teacherpersonal perspective, which includes other aspects such as beliefs and identity, should be joined to the teacher-knowledge perspective. Also, with the limitations related to research on mathematics teachers' knowledge, Skott (2013) indicates that these studies suggest that there are types of mathematical knowledge and ways of knowing that are essential to teachers' practices. Unfortunately, teachers can't acquire these by simply taking a standard university course. Therefore, "a more processual and participatory understanding is needed of what it means to know" (Skott, 2013, p.551).

The interest of research on teachers' identity is more recent compared to research on teachers' beliefs and knowledge. Research of teacher identity has generally adopted a social participationist approach. It sustains a processual highlighting. Researchers generally view identity "as fluid and always in the making, as tales of being and becoming as they relate to simultaneous engagement in multiple, social practices" (Skott, 2011, p.212). In this regard, identity is considered as a more dynamic construct than knowledge and beliefs (Sfard \& Prusak, 2005; Skott, 2011; Wagner and HerbelEisenmann, 2009).

Skott's view of identity is in line with the work of Wenger (1998) and Holland et al. (1998). Holland et al.'s (1998) theory is a sociocultural practice theory of identity and self. It sheds light on identity forming in process or activity. Holland et al. view identity as a dynamic co-constructed cultural phenomenon; identity forms in response to specific contexts and through time. Identity is the self-understandings of who we think we are. According to Holland et al. (1998), people's behaviour is mediated by their sense of self. "People tell others who they are, but even more important, they tell themselves and then try to act as though they are who they say they are" (p. 3). 
The aim of Holland et al.'s theory is to establish an understanding of a person's developing identity and its link with activity, or as they name it "identity in practice". The constructs of "practiced identities" can be understood in four contexts of activity: the figured worlds, positionality, space of authoring, and making worlds.

The PoP framework views teachers' identity as being how teachers narrate and position themselves in relation to multiple, and sometimes conflicting, figured worlds. Teachers don't position themselves merely by the contents of their verbal actions, "but by how [they move] in the classroom, how [they] - possibly unreflectively-react to disruptive behaviour, and the assertion with which [they] address their colleagues in staff meetings" (Skott, 2013, p. 551). However, this view of teachers' identity leads to empirical issue of understanding "how the significance, meanings, and mutual relationships of these narratives relate to her contributions to the practices that emerge in the classroom" (p. 551). To address this issue, Skott (2013) adopts a situated perspective on identity, which perceives identity as not equal to the self but as something that focuses on the changing versions of the me that occur through contact with others.

Skott's view of identity resonates with Wenger's (1998) conception of identity which is to some extent similar to Holland et al.'s (1998) view. Wenger (1998) has extended his practice-based theory of learning to incorporate issues of identity into processes of learning. He conceptualizes learning as an aspect of identity and identity as a result of learning. Also, he emphasizes the role of social practices in the developing of identity. "Learning transforms our identities. It transforms our ability to participate in the world by changing all at once who we are, our practices, and our communities" (p.226). "Identity is a becoming", therefore identity is lived, negotiated and constructed through a process of social interactions in our communities. According to Wenger (1998), the process of creating identity is inescapable and continuous. How we construct knowledge about our identity and how we interpret our position are negotiated in the course of our social interaction with others.

\section{Patterns-of-participation: The promise and limitations}

In classrooms, students and teachers interact in several simultaneous practices. Some of these practices are directly related to the teaching and learning of mathematics while others are not. Some of them are discourse related to an explicit verbal feature, while others are not. And some of them relate to communities that are not actually present in the classroom or at the school.

The teacher contributes to the constant creation of classroom practices. S/he engages in varied actions such as "repeating procedural explanations, solving disciplinary problems, ensuring a student's position in the classroom community, and taking a child's problematic home situation into account" (Skott, 2011, p. 213). Within all that, patterns from the teacher's previous experience in social engagements are enacted, integrated, merged and sometimes changed beyond recognition as they meet, combine with, convert, and further develop those that are associated with the immediate social circumstances (Skott, 2013). 
Researchers could use PoP as a coherent, participatory framework that has the potential to address issues usually faced within in distinct fields of teachers' knowledge, beliefs, and identity. However, PoP does not connect the analyses of teachers' knowledge, beliefs, and identity by regulating the use of theoretical views across the acquisition-participation part. As an alternative, it employs a participatory approach and looks for patterns in individual teacher's participation in different social practices. Therefore, PoP is a framework that could enrich the research approach in mathematics education, especially ones that are interested in understanding and theorising about mathematics teaching.

Patterns-of-participation research applies methodical triangulation including instance interviews that contain stimulated recall, observations, and document analyses, which is similar to the methods used in belief research. However, although the methods used in the two fields (beliefs and PoP) are the same, the intention behind the use of a combination of the methods is vastly different. "In patterns-of-participation research we do not assume that one might get better access to the true character of contextually and temporally stable constructs like beliefs. Different methods are used exactly because they may shed light on decidedly different forms of practice and decidedly different modes of participating in them" (Skott, 2011, p.34).

As a framework, PoP directs the research questions, shapes the research design, and controls data gathering and analysis. The research questions for PoP include asking about the role of teacher's stories of themselves as professional in their classroom engagement, the impact of teachers' relation to educational discourses such as the reform adoption, and the connection between how teachers engage with mathematics in and outside classroom contexts. The questions are, however, dependent on the personin-practice. Also, the design of the research should, as much as possible, permit access to teachers' practices and figured worlds beyond the classroom. "The unit of analysis may then be described as the teacher-in-multiple-practices- and-figured worlds as they relate to classroom interaction" (Skott, 2013, p.552).

PoP is an encouraging framework that could enrich research about understanding mathematics teaching; however, the theory has its limitations. The main limitation of the theory, in my opinion, is a methodological one. According to PoP, in order to understand teachers' immediate actions in the classroom, we should be able to have access to all the practices and figured worlds that are likely to be significant for immediate classroom interaction. This presents a major difficulty since the researcher cannot have access to all the past and present practices that are significant for the immediate classroom interaction.

Another limitation of this framework is the difficulty in identifying an individual's patterns-of-participation in settings over a short time. PoP adopts a participant approach of learning and knowing. PoP views the practices in the mathematics classroom as an ever-evolving result of individual and communal acts of meaningmaking on the part of the teacher and the students. Therefore, according to this view, applying the PoP framework requires close observation for a long period of time in order to identify the PoP through the ever-evolving process of teaching practice.

Finally, the PoP framework does not shed light on the influence of the patternsof-participation of students' mathematics learning experience. It seems that this 
framework aims to theorize about mathematics teaching without giving enough attention to the mathematics learning experience from the students' perspective. This theory does not explain explicitly the value of patterns-of-participation in relation to students' learning, which is the main purpose of teaching.

\section{References}

Ball, D. L., Thames, M. H., \& Phelps, G. (2008). Content knowledge for teaching: What makes it special? Journal of Teacher Education, 59(5), 389-407.

Blumer, H. (1969). Symbolic interactionism: Perspective and method. Berkeley: University of Los Angeles Press

Gates, P. (2006). Going Beyond Belief Systems: Exploring a Model for the Social Influence on Mathematics Teacher Beliefs. Educational Studies in Mathematics 63(3), 347-369.

Holland, D., Skinner, D., Lachicotte, W, Jr, \& Cain, C. (1998). Identity and agency in cultural worlds. Cambridge, MA: Harvard University Press.

Kilpatrick, J. (1992). A history of research in mathematics education. In D. A. Grouws (Ed.), Handbook of research on mathematics teaching and learning (pp. 3-38). New York: Macmillan

Lave, J. and Wenger, E. (1991): Situated learning: legitimate peripheral participation, Cambridge, Cambridge University Press

Lerman , S. (2002). Situating research on mathematics teachers' beliefs and on change. In G. C. Leder, E. Pehkonen, \& G. To"rner (Eds.), Beliefs: A hidden variable in mathematics education? (pp. 233-243). Dordrecht, The Netherlands: Kluwer Academic Publishers

Lerman, S.: 2000, The social turn in mathematics education research. In J. Boaler (Ed.) Multiple Perspectives on Mathematics Teaching and Learning. (pp. 19-44) Westport, CT: Ablex.

Lerman, S. (2001). Cultural, discursive psychology: A sociocultural approach to studying the teaching and learning of mathematics. Educational Studies in Mathematics, $46,87-113$

Liljedahl, P., Oesterle, S. \& Bernèche, C. (2012). Stability of beliefs in mathematics education: a critical analysis. Nordic Studies in Mathematics Education,17(3-4), 101-118.

Liljedahl, P., Oesterle, S. \& Bernèche, C. (2009). Beliefs as dynamic: old light through a new window. Paper presented at MAVI 15 in Genoa Italy, 2009. 
Lester, F. K. (2002). Implications for research on students' beliefs for classroom practice. In G. C. Leder, E. Pehkonen, \& G. Torner (Eds.), Beliefs: A hidden variable in mathematics education? (pp. 345-353). Dordrecht: Kluwer.

McLeod, D. B., \& McLeod, S. H. (2002). Synthesis-Beliefs and mathematics education: Implications for learning, teaching, and research. In G. C. Leder, E. Pehkonen,\&G. Torner (Eds.), Beliefs: A hidden variable in mathematics education? (pp. 115123). Dordrecht, The Netherlands: Kluwer Academic Publishers

McLeod, D. (1992). Research on the affect in mathematics education: A reconceptualization. In D. A. Grouws (ed.) Handbook of Research on Mathematics Teaching and Learning, pp. 575-596. New York: Macmillan.

Pajares, M. F. (1992). Teachers' Beliefs and Educational Research: Cleaning Up a Messy Construct. Review of Educational Research, 62 (3), 307-332

Speer, N. (2005). Issues of methods and theory in the study of mathematics teachers' professed and attributed beliefs, Educational studies in mathematics, 58(3), 361391.

Sfard, A. (2008). Thinking as communicating:Human development, the growth of discourses, and mathematizing. Cambridge, U.K.: Cambridge University Press

Sfard, A. (1998). On two metaphors for learning and the dangers of choosing just one. Educational Researcher, 27(2), 4-13.

Sfard, A. (2001). There is more to discourse than meets the ears: Looking at thinking as communicating to learn more about mathematical learning. Educational Studies in Mathematics, 46(1), 13-57.

Skott, J. (2010). Shifting the direction of belief research: From beliefs to patterns of participation. In M.F. Pinto \& T.F. Kawasaki (Eds.), Proceedings of the 34th Conference of the International Group for the Psychology of Mathematics Education, 4, 193-200. Belo Horizonte, Brazil: PME

Skott, J., Moeskær Larsen, D. \& Hellsten Østergaard, C. (2011). From beliefs to patterns of participation - shifting the research perspective on teachers. Nordic Studies in Mathematics Education, 16(1-2), 29-55.

Skott, J. (2009). Contextualising the notion of belief enactment. Journal of Mathematics Teacher Education, 12(1), 27-46.

Skott, J. (2013). Understanding the role of the teacher in emerging classroom practices: searching for patterns of participation. ZDM Mathematics Education, 45(4), 547559 . 
Skott, J. (2011). Beliefs vs. patterns of participation - towards coherence in understanding the role the teacher. In B. Roesken \& M. Casper (Eds.), Proceedings of the 17th Conference of Mathematical Views, 211-220. Bochum, Germany: MAVI.

Tirosh, D., \& Graeber, A. (2003). Challenging and changing mathematics teaching classroom practices. In A. Bishop, M. Clements, C. Kietel, J. Kilpatrick, \& F. Leung (Eds.), Second international handbook of mathematics education (pp. 643-688). Dordrecht, the Netherlands: Kluwer Academic Publishers

Thompson, A. (1992). Teachers' beliefs and conceptions: A synthesis of research. In D. A. Grouws (ed.) Handbook of Research on Mathematics Teaching and Learning (pp. 127-146). New York: Macmillan

Wagner, D., \& Herbel-Eisenmann, B. (2009). Re-mythologizing mathematics through attention to classroom positioning. Educational Studies in Mathematics, 72(1), 115 .

Wilson, S., \& Cooney, T. (2002). Mathematics teacher change and development. In G. C. Leder, E. Pehkonen, \& G. To" rner (Eds.), Beliefs: A hidden variable in mathematics education? (pp. 127-147). Dordrecht, The Netherlands: Kluwer Academic Publishers

Wenger, E., McDermott, R., \& Snyder, W. (2002). Cultivating communities of practice. Boston: Harvard Business School Press

Wenger, E. (1998). Communities of practice: Learning, meaning, and identity. Cambridge: Cambridge University Press. 